\title{
ORIGINAL
}

\section{The Passive Radon-Thoron Discriminative Dosimeter for Practical Use}

\author{
Masahiro DoI ${ }^{* * * 1}$ and Sadayoshi KoBAYASHI $* *, * 1$
}

(Received July 28, 1993)

(Accepted January 6, 1994)

\begin{abstract}
A passive radon-thoron discriminative dosimeter for practical use has been developed. The body of the practical R-T dosimeter is made of two hemispheric diffusion chambers of carbonized plastic whose diameters are $110 \mathrm{~mm}$ and $70 \mathrm{~mm}$, respectively. These diameters are determined to improve the detection efficiency of radon as well as thoron and also the discrimination ratio of radon to thoron. Inner surface of the detector housing is smooth and free from electrified charge to assure the uniform deposition of radon and thoron progeny, because the detector housing is molded out of carbonized plastic as an anti-static material. In addition, structure of an air inlet has improved to contact more tightly with a glass fiber filter to prevent dust from entering the detector housing. The air inlet of the detector housing is also covered with a half-cutted hemispherical windbreak to protect the glass fiber filter from weathering and to stabilize the influence of convectional air flow on the radon and thoron entry rate into two hemispherical diffusion chambers of the dosimeter. The results of calibration exercises showed that the lower detection limit of radon and thoron concentrations were estimated to be $5.1 \mathrm{Bqm}^{-3}$ and $7.9 \mathrm{Bqm}^{-3}$ respectively in 2 months exposure. And an interim measurement in the concrete cellar proved that the practical R-T dosimeter has enough specifications to be used in the large-scale radon-thoron discriminative survey.
\end{abstract}

KEY WORDS: radon, thoron, SSNTD, polycarbonate, electrochemical etching, passive method

\section{INTRODUCTION}

Special attention has been drawn to the indoor radon concentration, since radon $\left({ }^{222} \mathrm{Rn}\right)$ and radon progeny indoors contribute the largest dose of exposure to the population at large among natural radiation sources. ${ }^{1,2)}$ Indoor thoron $\left({ }^{220} \mathrm{Rn}\right)$ and its progeny, however, have not been taken seriously in the national surveys in many countries. Since it is assumed for some reason or other that indoor thoron and its progeny have not been regarded to contribute to the effective dose of the general public significantly in comparison with the

*土居雅広, ** 小林定喜

*1 Safety Analysis Unit, National Institute of Radiological Sciences; 4-9-1, Anagawa, Inage, Chiba, 263 Japan.

放射線医学総合研究所総括安全解析研究官付; 千葉市稲毛 区穴川 4-9-1 (开263) indoor radon and its progeny.

In Japan, however, there are some leading studies which suggested in the early stages that the enhanced concentrations of thoron and thoron progeny tend to be found in the Japanese-style house whose interior wall is covered with fine soil as a surface coat. $^{3-5}$ ) And there are other studies which suggested that thoron and its progeny would contribute to the inhabitant a considerable effective dose. ${ }^{6-8)}$ These findings are consistent with the thorium content of the wall materials as well as radium's. ${ }^{9}$

In order to estimate indoor radon and thoron concentrations over a longer period, the authors developed a new type of passive dosimeter (prototype R-T dosimeter) which could estimate radon and thoron concentrations differentially. ${ }^{10,11)} \mathrm{A}$ preliminary measurement of the typical Japanesestyle house suggested that indoor thoron concen- 


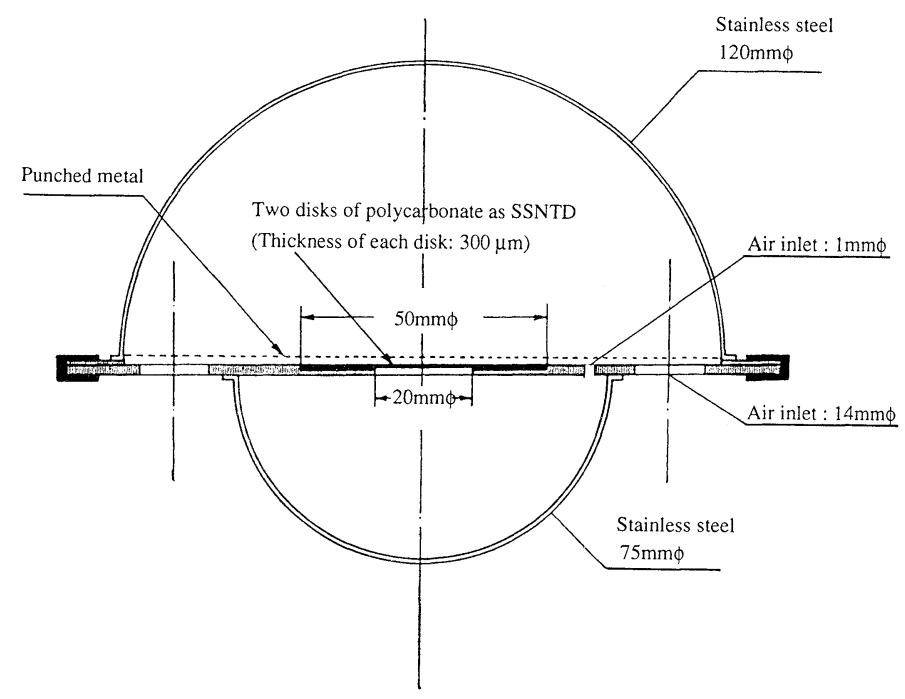

Fig. 1 A schematic diagram of the prototype passive radon-thoron discriminative dosimeter (prototype R-T dosimeter).

tration had a spatial distribution that decreases exponentially with the distance from the interior wall. ${ }^{12)}$ And a preliminary survey of the indoor radon and thoron concentrations in the 42 rooms of 21 Japanese-style houses in Hiroshima Prefecture was performed in 1992. ${ }^{13)}$ In the survey, dosimeters were placed at $20 \mathrm{~cm}$ from the surface of the interior wall, and the results showed that arithmetic mean of indoor radon and thoron concentrations were $25.6 \pm 1.1(\mathrm{SEM}) \mathrm{Bq} \mathrm{m}^{-3}$ and $84.3 \pm 15.9$ (SEM) $\mathrm{Bq} \mathrm{m}^{-3}$ respectively; $\mathrm{SEM}$ is an acronym of "standard error of the mean." It also proved that indoor thoron concentration had a wide range from zero to $546.6 \mathrm{~Bq} \mathrm{~m}^{-3}$, and enhanced concentrations of thoron were found in some Japanese-style rooms with interior soil wall and tatami flooring. According to the national statistics, ${ }^{14)}$ around $73 \%$ of all the Japanese houses are classified as "wooden house" of which interior wall is generally coated with mud (or fine soil) which may be a source of indoor thoron as well as radon. Taking these findings into consideration, nationwide survey of indoor thoron concentration should be planned and performed as a screening of the houses with enhanced concentration of thoron progeny.

The objective of the present study is first to investigate some specifications concerning the design of the radon-thoron discriminative dosimeter for practical use (practical R-T dosimeter) which is suitable for the large-scale indoor radon and thoron survey, and second, results of the calibration exercises and in-situ measurements are introduced with some discussions.

\section{PROCEDURES IN THE DEVELOPMENT OF A PRACTICAL R-T DOSIMETER}

1. Specifications of the prototype R-T dosimeter-A review

Figure 1 illustrates a schematic diagram of the prototype R-T dosimeter. A body of the detector housing is made of stainless steel, which has two hemispheric chambers whose diameters are 120 $\mathrm{mm}$ and $75 \mathrm{~mm}$, respectively. These hemispheric chambers cover the detector holder, which is a stainless steel disk of $3 \mathrm{~mm}$ thickness whose diameter is $135 \mathrm{~mm}$. Two disks of polycarbonate film (Iupilon ${ }^{\circledR \dagger}{ }^{\dagger}$ FE-2000, $300 \mu \mathrm{m}$ in thickness, 50 $\mathrm{mm} \phi$ ) are installed in the detector holder, one film faces the inside of $120 \mathrm{~mm} \phi$ hemispheric chamber and another faces the inside of $75 \mathrm{~mm} \phi$ hemispheric chamber. Eight air inlets of $14 \mathrm{~mm} \phi$ are provided on the detector holder, and they are covered with glass fiber filters to prevent progeny from entering the detector housing.

The radon and thoron gases are first introduced

$\dagger$ Iupilon $\otimes$ (type FE-2000 for printing) is a trade mark of the polycarbonate film produced by Mitsubishi Gas Chemical Company, Inc., Mitsubishi Bld. 2-5-2, Marunouchi, Chiyoda-ku, Tokyo 100, Japan. 
into the $120 \mathrm{~mm} \phi$ hemispheric chamber, and then, diffuse into the $75 \mathrm{~mm} \phi$ hemispheric chamber through a pinhole air inlet $(1 \mathrm{~mm} \phi)$ which is also provided on the detector holder. After the exposure to the environment for 2 months, detector films are subjected to preliminary chemical etching (CE) with a blend of $8.0 \mathrm{~N} \mathrm{KOH}$ solution $(80 \%$ by volume) and $\mathrm{C}_{2} \mathrm{H}_{5} \mathrm{OH}(20 \%$ by volume) at $30^{\circ} \mathrm{C}$, and electrochemical etching (ECE) supplying the high voltage and high frequency electric power (AC800 V, $2 \mathrm{kHz}$ ). Polycarbonate film in the $120 \mathrm{~mm} \phi$ hemispheric chamber is subjected to preliminary chemical etching (CE) for $3 \mathrm{~h}$ and electrochemical etching (ECE) for $3 \mathrm{~h}$ to register $\alpha$-tracks originated from thoron and its progeny predominantly together with small contribution of radons. Polycarbonate film in the $75 \mathrm{~mm} \phi$ hemispheric chamber is subjected to preliminary chemical etching (CE) for $30 \mathrm{~min}$ and electrochemical etching (ECE) for $3 \mathrm{~h}$ in order to register $\alpha$-tracks originated from radon and its progeny predominantly together with negligible contribution of thoron and its progeny. Detailed specifications of the prototype R-T dosimeter are available elsewhere. ${ }^{11)}$

\section{Design concept of a practical passive radon- thoron discriminative dosimeter}

Major specifications improved in the practical R-T dosimeter are summarized as follows:

(1) Determination of the diameters of two hemispheric chambers

Monte Carlo simulation was used in the determination of the diameters of two hemispheric chambers. In the Monte Carlo simulation, etch pit formation model during $\mathrm{CE}$ and ECE in polycarbonate foil ${ }^{10)}$ was used to simulate the calibration factor (tracks $\mathrm{cm}^{-2}$ per $\mathrm{Bq} \mathrm{m}{ }^{-3} \mathrm{~d}$ ) for radon and thoron concentrations. The model explains the mechanism on the formation of electrochemical etch pits based on the MASON's theory ${ }^{15,16)}$ as follows:

(a) Originally, an $\alpha$-trajectory formed in the polycarbonate film is transformed into chemical etch cone by conventional chemical dissolution,

(b) Chemical etch cone is transmuted into a round chemical etch pit, if $D f_{\mathrm{PC}}\left(E_{\mathrm{i}}\right)$ of the $\alpha$-trajectory is included in the CE layer,

(c) Chemical etch cone is converted into an electrochemical etch pit by electric discharge, if $D f_{\mathrm{PC}}\left(E_{\mathrm{i}}\right)$ of the $\alpha$-trajectory is in the ECE layer,

where $D f_{\mathrm{PC}}\left(E_{\mathrm{i}}\right)(\mu \mathrm{m})$ is an effective vertical mean range, and $E_{\mathrm{i}}(\mathrm{MeV})$ is an incident energy. Therefore, relative location between $D f_{\mathrm{PC}}\left(E_{1}\right)$ and the depth of ECE layer is the determinant whether an $\alpha$-track can be registered as electrochemical etch pits or not.

$D f_{\mathrm{PC}}\left(E_{\mathrm{i}}\right)$ is described as a function of the extrapolated mean range of the $\alpha$-particle, $D_{\mathrm{PC}}\left(E_{\mathrm{1}}\right)$ $(\mu \mathrm{m}) . \quad D_{\mathrm{PC}}\left(E_{\mathrm{i}}\right)$ is estimated by the following equation:

$$
D_{\mathrm{PC}}\left(E_{\mathrm{i}}\right)=\left(R_{\mathrm{air}}\left(E_{0}\right)-L\right) \times S P_{\mathrm{air}} / S P_{\mathrm{PC}} \times \cos \theta
$$

where $R_{\mathrm{air}}\left(E_{0}\right)(\mathrm{mm})$ is the extrapolated $\alpha$-range in dry air $\left(760 \mathrm{mmHg}, 15^{\circ} \mathrm{C}\right), E_{0}(\mathrm{MeV})$ is the initial energy of $\alpha$-particle, $L(\mathrm{~mm})$ is the flight length of $\alpha$-particle in air, $\theta$ is the incident angle, and $S P_{\mathrm{air}} / S P_{\mathrm{PC}}$ is the ratio of relative stopping power of air to that of polycarbonate, which is estimated to be $0.87\left(\mu \mathrm{m} \mathrm{mm}^{-1}\right)$.

The regression analysis between the etch pit diameter and the depth of ECE layer indicated the quantitative relationship between $D f_{\mathrm{PC}}\left(E_{\mathrm{i}}\right)$ and $D_{\mathrm{PC}}\left(E_{\mathrm{i}}\right)$ as follows:

$$
\begin{aligned}
& D f_{\mathrm{PC}}\left(E_{\mathrm{i}}\right)=D_{\mathrm{PC}}\left(E_{\mathrm{i}}\right)+3.414-3.395 \ln \left(D_{\mathrm{PC}}\left(E_{\mathrm{i}}\right)\right) \\
& \quad(r=0.998)
\end{aligned}
$$

where the constant of 3.414 and 3.395 were determined with the regression analysis. Details of the vertical effective mean range of the $\alpha$-particle in the polycarbonate film were shown by Dor $e t$ al. ${ }^{10)}$

The thickness of the layer removed by preliminary CE, $V$ (in $\mu \mathrm{m}$ ) is estimated as follows:

$V=3.57 \times T_{\mathrm{CE}}$

where $T_{\mathrm{CE}}(\mathrm{h})$ is the duration of $\mathrm{CE}$, and the constant of $3.57\left(\mu \mathrm{m} \mathrm{h}^{-1}\right)$ is the bulk etching rate of the polycarbonate film (Iupilon ${ }^{\circledR}$ ) at $30^{\circ} \mathrm{C}^{17}{ }^{17}$ Similarly, the thickness of the totally removed layer by $\mathrm{CE}$ and ECE, $\mathrm{H}$ (in $\mu \mathrm{m}$ ) is estimated as follows:

$$
H=3.57 \times\left(T_{\mathrm{CE}}+T_{\mathrm{ECE}}\right)
$$

where $T_{E C E}(\mathrm{~h})$ is the duration of ECE. Monte Carlo simulation was performed to estimate the location of $D f_{\mathrm{PC}}\left(E_{1}\right)$ in the polycarbonate film and to calculate the component ratio of $D f_{\mathrm{PC}}\left(E_{\mathrm{i}}\right)$ which are included in the ECE layer $\left(V<D f_{\mathrm{PC}}\left(E_{1}\right)<\right.$ $H)$.

The initial energy of $\alpha$-particle, $E_{0}(\mathrm{MeV})$ is fixed to $5.49,6.00,7.69,6.29,6.78,6.05$ and 8.78 $\mathrm{MeV}$ for ${ }^{222} \mathrm{Rn},{ }^{218} \mathrm{Po},{ }^{214} \mathrm{Po},{ }^{220} \mathrm{Rn},{ }^{216} \mathrm{Po},{ }^{212} \mathrm{Bi}$ and ${ }^{212} \mathrm{Po}$, respectively. In the Monte Carlo simulation, ${ }^{218} \mathrm{Po},{ }^{214} \mathrm{Po},{ }^{212} \mathrm{Bi}$ and ${ }^{212} \mathrm{Po}$ are assumed 
to be deposited on the inner surface of the detector housing, on the other hand, ${ }^{222} \mathrm{Rn},{ }^{220} \mathrm{Rn}$ and ${ }^{216} \mathrm{Po}$ are assumed to fill the hemispheric chamber uniformly.

Concerning the etching period, $T_{\mathrm{ECE}}$ was limited to $3 \mathrm{~h}$ to avoid the pinhole penetration of the polycarbonate film $\left(300 \mu \mathrm{m}^{\mathrm{t}}\right)$ which is triggered by the electric breakdown. In addition, total etching period $\left(T_{\mathrm{CE}}+T_{\mathrm{ECE}}\right)$ should be limited up to $6 \mathrm{~h}$ since the component of the etching solution (etchant) is changed by the dissolution of the polycarbonate film into the etchant and the evaporation of $\mathrm{C}_{2} \mathrm{H}_{5} \mathrm{OH}$. Therefore, preliminary chemical etching is limited to $3 \mathrm{~h}$. In the case of $3 \mathrm{~h} \mathrm{CE}$ and $3 \mathrm{~h} \mathrm{ECE}, \alpha$-particles with relatively high incident energies $(2.5-4.0 \mathrm{MeV}$, vertical incidence) are detected.

On the other hand, preliminary CE should be performed more than $30 \mathrm{~min}$ in order to remove the scratches on the surface of detector film. In the case of CE $30 \mathrm{~min}$ and ECE $3 \mathrm{~h}$, $\alpha$-particle with relatively low incident energies $(0.8-2.7 \mathrm{MeV}$, vertical incidence) are detected. In the Monte Carlo calculation, $T_{\mathrm{CE}}$ was varied stepwise from $30 \mathrm{~min}(0.5 \mathrm{~h})$ to $3 \mathrm{~h}$ in every $30 \mathrm{~min}(0.5 \mathrm{~h})$, and the diameter of hemispheric chamber was varied stepwise from $50 \mathrm{~mm}$ to $120 \mathrm{~mm}$ in every $10 \mathrm{~mm}$ to optimize diameters of two hemispheric chambers as well as $T_{\mathrm{CE}}$.

(2) Improvement in the design of an air inlet

The detection efficiency of thoron is influenced by physical conditions of the glass fiber filters which cover eight air inlets of $14 \mathrm{~mm} \phi$. In the prototype R-T dosimeter, however, these glass fiber filters are not prevented from being stuffed with dust nor weathering due to environmental agents. Therefore, a windbreak is newly designed to cover an air inlet of practical R-T dosimeter to protect the glass fiber filters. And in addition, windbreak is expected to cancel the influence of the wind on the air exchange rate of the detector housing. Figure 2 shows the schematic figure of windbreak which was designed in this study.

To determine the height of the windbreak where the air exchange rate $\left(\mathrm{h}^{-1}\right)$ of the detector housing is stabilized, gas chromatography (sample gas: $\mathrm{SF}_{6}$ gas, carrier gas: $\mathrm{N}_{2}$ gas) was performed to estimate the air exchange rate when the dosimeter was blown with the forced air flow by electric fan at the velocities of $0.5 \pm 0.5 \mathrm{~m} \cdot \mathrm{s}^{-1}$ (Case 1), $2.0 \pm 1.0 \mathrm{~m} \cdot \mathrm{s}^{-1}$ (Case 2) and $6.0 \pm 1.0$

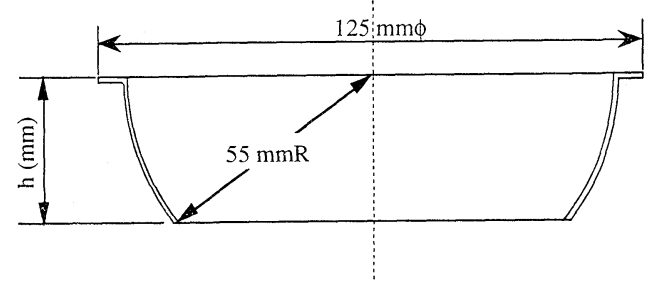

Fig. 2 A schematic diagram of the windbreak with which the passive radon-thoron discriminative dosimeter for practical use (practical R-T dosimeter) is equipped.

$\mathrm{m} \cdot \mathrm{s}^{-1}$ (Case 3).

(3) Quality control in the mass production of the dosimeter

Quality control in the mass production of the dosimeter depends predominantly on the uniformity in the production of detector housing. Casting the plastic into the shape of detector housing is one of the effective ways to establish the uniformity of the products. As the material of detector housing, static-free plastic should be used to avoid the electric charge on the inner surface of detector housing which causes the uneven deposits of radon and thoron progeny which are generally charged positively. ${ }^{18)}$

In the selection of the plastic material, radioactive contents of $\alpha$-emitters (e.g. radium and thorium) must be taken into consideration since they raise the background track density. Taking these requirements into consideration, carbonated polycarbonate plastic ${ }^{\dagger \dagger}$ was selected as the material of detector housing since it has low electric resistance $\left(<5.3 \times 10^{3} \Omega \mathrm{cm}\right)$ and negligible radioactivity.

To estimate the background track density, twenty pieces of the practical R-T dosimeter were exposed to the radon-free air for 2 months. Another twenty dosimeters were placed in the concrete cellar for 2 months to estimate the variance among these dosimeters.

(4) Simplification in the assemblage of the practical R-T dosimeter

With regard to the prototype R-T dosimeter, it takes a lot of time to assemble several parts into the shape of dosimeter. Therefore, the procedure in the assemblage was simplified in the practical

$\dagger \dagger$ Carbonate polycarbonate plastic is a product of Lion Corporation, Chemical Products Division, 1-2-22, Yokoami, Sumida-ku, Tokyo 130, Japan. 
R-T dosimeter. These revisions could be realized because the carbonated polycarbonate plastic was casted into the metal mold of any shape and design. Convenient attachments were also equipped to ease the handling of the practical R-T dosimeter.

\section{Confirmation of the specifications of the prac-} tical R-T dosimeter

In order to verify the specifications of the practical R-T dosimeter, calibration exercises were performed using a standard radon chamber at Nagoya University and standard radon-thoron mixed chamber at Waseda University in October, 1992.

\section{RESULTS AND DISCUSSION}

1. Determination of the diameters of two hemispheric diffusion chambers

Two hemispheric diffusion chambers must be designed to enhance the quality of the discriminative measurement of radon and thoron concentrations. As primary specification, the practical R-T dosimeter must have enough detection efficiency to evaluate a quite low concentration of radon accurately. In the present study, the lower detection limit of radon concentration in the case of 2 months exposure is set to be $5 \mathrm{~Bq} \mathrm{~m}{ }^{-3}$, which is equivalent to an interim world-wide average of outdoor radon concentration. ${ }^{2)}$

To estimate the background track density (track $\mathrm{cm}^{-2}$ ) of the Iupilon ${ }^{\circledR}$, twenty pieces of the prototype R-T dosimeter were exposed to the research air for three months. As the result, the background track density was $(0.0556 \pm 0.0244) T$, where $T(\mathrm{~d})$ is an exposure period. ${ }^{10)}$ The lower detection limit can be defined as $4.65 \sigma_{B}$, where $\sigma_{\mathrm{B}}$ is a standard deviation of the background track density. ${ }^{19)}$ Consequently, a calibration factor for radon concentration should be more than 0.0378 (tracks $\mathrm{cm}^{-2}$ per $\mathrm{Bq} \mathrm{m^{-3 }}$ d) to detect the radon concentration of more than $3 \mathrm{~Bq} \mathrm{~m}^{-3}$.

In addition, calibration factors for both radon and thoron should be selected to enhance the discrimination ratio between radon and thoron, which was defined as RCF, the ratio of calibration factor of radon to thoron. To estimate both radon and thoron concentrations accurately and simultaneously, RCF should be minimized in the larger hemispheric chamber to detect thoron dominantly, and it should be maximized in the smaller one to detect radon mainly.
Table 1 shows the conversion factors for iadon and thoron concentrations (tracks $\mathrm{cm}^{-2}$ per $\mathrm{Bq}$ $\left.\mathrm{m}^{-3} \mathrm{~d}\right)$ which were estimated by Monte Carlo simulation. In the simulation, a diameter of the hemispheric chamber varied stepwise from $50 \mathrm{~mm}$ to $120 \mathrm{~mm}$ in every $10 \mathrm{~mm}$ and a preliminary CE varied stepwise from $0.5 \mathrm{~h}$ to $3 \mathrm{~h}$ in every $0.5 \mathrm{~h}$. In all cases, following ECE was fixed as $3 \mathrm{~h}$. Table 2 indicates the RCF value in each cell of the matrix in Table 1.

Radon conversion factor for the polycarbonate film in the small hemispheric chamber was the determinant of the detection efficiency for radon concentration. Since the general level of indoor concentration was considered to be low (10-20 $\mathrm{Bq} \mathrm{m}^{-3}$ ), lower detection limit for the radon concentration was designed to be less than $3 \mathrm{~Bq}$ $\mathrm{m}^{-3}$. Therefore, as shown above, radon conversion factor for the polycarbonate film in the small hemisphere should be more than 0.0378 (tracks $\mathrm{cm}^{-2}$ per $\mathrm{Bq} \mathrm{m} \mathrm{m}^{-3} \mathrm{~d}$ ). Table 1 shows that the conversion factor for radon concentration increases as the $\mathrm{CE}$ decreases. In the case of $\mathrm{CE} 0.5 \mathrm{~h}$, the diameter of the small hemispheric chamber should be more than $60 \mathrm{~mm}$ to satisfy the above condition. However, as shown in Table 2, the diameter should be as small as possible to maximize the RCF value. Consequently, to balance the two objective functions, the diameter of the small hemispheric chamber is optimized to be $70 \mathrm{~mm}$ in the case of CE $0.5 \mathrm{~h}$ and ECE $3 \mathrm{~h}$.

On the other hand, large hemispheric chamber is designed to detect thoron concentration mainly, its conversion factor for thoron concentration should be maximized. To satisfy this objective function, Table 1 shows that conversion factor for thoron concentration increases as the $\mathrm{CE}$ increases. In the case of $\mathrm{CE} 3 \mathrm{~h}$, the diameter of the large hemispheric chamber should be as large as possible. However, as shown in Table 2, the diameter is optimized to be $110 \mathrm{~mm}$ in the case of CE $3 \mathrm{~h}$ to minimize the RCF value. Consequently, the diameter of the large hemispheric chamber is optimized to be $110 \mathrm{~mm}$ in the case of $\mathrm{CE} 3 \mathrm{~h}$ and ECE $3 \mathrm{~h}$.

\section{Determination of the shape of windbreak attached to the air inlet}

Figure 3 illustrates the air exchange rate $\left(\mathrm{s}^{-1}\right)$ of the prototype R-T dosimeter through eight air inlets $(14 \mathrm{~mm} \phi)$ which was estimated by gas chromatography using $\mathrm{SF}_{6}$ as sample gas and $\mathrm{N}_{2}$ 
Table 1 The conversion factors of track density (tracks $\mathrm{cm}^{-2}$ ) into radon and thoron exposures $\left(\mathrm{Bq} \mathrm{m}^{-3} \mathrm{~d}\right)$ which are estimated by Monte Carlo simulation.

Conversion factors for radon concentration (tracks $\mathrm{cm}^{-2}$ per $\mathrm{Bq} \mathrm{m}^{-3} \mathrm{~d}$ )

\begin{tabular}{ccccccccc}
\hline \multirow{2}{*}{$\begin{array}{c}\text { CE } \\
\text { (h) }\end{array}$} & \multicolumn{7}{c}{ Diameter of hemispheric diffusion chamber (mm) } \\
\cline { 2 - 8 } & 50 & 60 & 70 & 80 & 90 & 100 & 110 & 120 \\
\hline 0.5 & 0.0148 & 0.0255 & $* 0.0375$ & 0.0407 & 0.0417 & 0.0437 & 0.0445 & 0.0457 \\
1.0 & 0.0203 & 0.0293 & 0.0361 & 0.0357 & 0.0368 & 0.0403 & 0.0410 & 0.0368 \\
1.5 & 0.0247 & 0.0312 & 0.0316 & 0.0317 & 0.0368 & 0.0380 & 0.0353 & 0.0263 \\
2.0 & 0.0274 & 0.0309 & 0.0298 & 0.0324 & 0.0356 & 0.0348 & 0.0285 & 0.0231 \\
2.5 & 0.0279 & 0.0287 & 0.0306 & 0.0327 & 0.0330 & 0.0302 & 0.0226 & 0.0215 \\
3.0 & 0.0266 & 0.0258 & 0.0302 & 0.0306 & 0.0294 & 0.0238 & $* 0.0202$ & 0.0198 \\
\hline
\end{tabular}

Conversion factors for thoron concentration (tracks $\mathrm{cm}^{-2}$ per $\mathrm{Bq} \mathrm{m} \mathrm{m}^{-3} \mathrm{~d}$ )

\begin{tabular}{lcccccccc}
\hline \multirow{2}{*}{$\begin{array}{l}\text { CE } \\
\text { (h) }\end{array}$} & \multicolumn{7}{c}{ Diameter of hemispheric diffusion chamber (mm) } \\
\cline { 2 - 8 } & 50 & 60 & 70 & 80 & 90 & 100 & 110 & 120 \\
\hline 0.5 & 0.0035 & 0.0099 & $* 0.0262$ & 0.0327 & 0.0444 & 0.0528 & 0.0591 & 0.0643 \\
1.0 & 0.0066 & 0.0151 & 0.0328 & 0.0381 & 0.0464 & 0.0525 & 0.0561 & 0.0612 \\
1.5 & 0.0108 & 0.0209 & 0.0375 & 0.0414 & 0.0477 & 0.0512 & 0.0548 & 0.0593 \\
2.0 & 0.0158 & 0.0271 & 0.0410 & 0.0442 & 0.0483 & 0.0508 & 0.0550 & 0.0573 \\
2.5 & 0.0214 & 0.0325 & 0.0436 & 0.0457 & 0.0482 & 0.0512 & 0.0552 & 0.0546 \\
3.0 & 0.0271 & 0.0367 & 0.0452 & 0.0465 & 0.0484 & 0.0522 & $* 0.0537$ & 0.0519 \\
\hline
\end{tabular}

Table 2 The ratio of radon to thoron conversion factors in the combination of CE from 0.5 to $3 \mathrm{~h}$ and the diameter of the hemispheric chamber from $50 \mathrm{~mm}$ to $120 \mathrm{~mm}$.

\begin{tabular}{lcccccccc}
\hline \multirow{2}{*}{$\begin{array}{c}\text { CE } \\
\text { (h) }\end{array}$} & \multicolumn{7}{c}{ Diameter of hemispheric diffusion chamber (mm) } \\
\cline { 2 - 9 } & 50 & 60 & 70 & 80 & 90 & 100 & 110 & 120 \\
\hline 0.5 & 4.23 & 2.59 & $* 1.43$ & 1.25 & 0.94 & 0.83 & 0.75 & 0.71 \\
1.0 & 3.10 & 1.94 & 1.10 & 0.94 & 0.79 & 0.77 & 0.73 & 0.60 \\
1.5 & 2.29 & 1.49 & 0.84 & 0.77 & 0.77 & 0.74 & 0.64 & 0.44 \\
2.0 & 1.73 & 1.14 & 0.73 & 0.73 & 0.74 & 0.69 & 0.52 & 0.40 \\
2.5 & 1.31 & 0.88 & 0.70 & 0.72 & 0.69 & 0.59 & 0.41 & 0.39 \\
3.0 & 0.98 & 0.70 & 0.67 & 0.66 & 0.61 & 0.46 & $* 0.38$ & 0.38 \\
\hline
\end{tabular}

as carrier gas. To simulate the convectional air flow, forced wind was generated by the electric fan. The wind velocity at the air inlets of the dosimeter were zero, $2.0 \pm 1.0 \mathrm{~ms}^{-1}$ and $6.0 \pm 1.0$ $\mathrm{m} \mathrm{s}^{-1}$ in Cases 1,2 and 3 respectively. In Case 1 , molecular diffusion of the sample gas was regarded as the determinant of gas exchange rate of the dosimeter. However, in Cases 2 and 3, the convectional air flow caused the negative air pressure at the air inlets of the dosimeter which accelerated the gas exchange rate. As shown in Fig. 3, the gas exchange rate was increased in proportion to the wind velocity.

This suggests that the detection efficiency of 


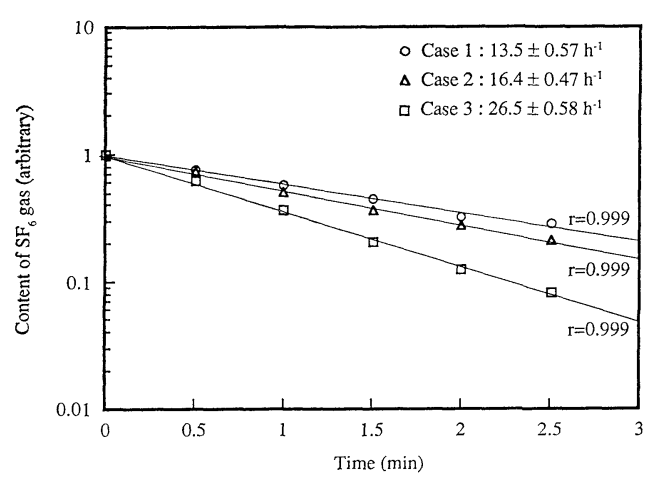

Fig. 3 The air exchange rate between the atmosphere and the $120 \mathrm{~mm} \phi$ hemispheric diffusion chamber of the prototype R-T dosimeter. The air exchange rate $\left(\mathrm{s}^{-1}\right)$ between the atmosphere and the $120 \mathrm{~mm} \phi$ hemispheric chamber through eight air inlets of $14 \mathrm{~mm} \phi$ was estimated by gas chromatography (sample gas: $\mathrm{SF}_{6}$, carrier gas: $\mathrm{N}_{2}$ ). To simulate the convectional air flow, forced wind was generated by the electric fan. The wind velocity at the air inlets of the dosimeter were zero, $2.0 \pm 1.0 \mathrm{~s}^{-1}$ and $6.0 \pm 1.0 \mathrm{~ms}^{-1}$ in Cases 1, 2 and 3 respectively.

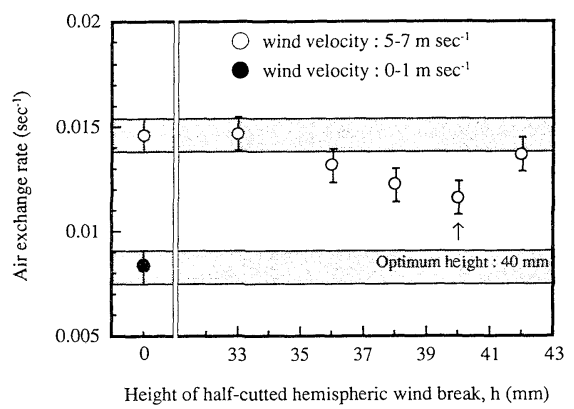

Fig. 4 The air exchange rate of the prototype R-T dosimeter equipped with half-cutted hemispherical windbreak of which height from the bottom was varied from 33 to $42 \mathrm{~mm}$ at the wind velocity of $6.0 \pm 1.0 \mathrm{~ms}^{-1}$.

the dosimeter was easily infiuenced by the convectional air flow. Especially for thoron, its entry rate in the detector housing should be widely influenced by the gas exchange rate of the dosimeter more directly than radon, because of the short half-life of thoron, only $56 \mathrm{~s}$.

To ease the influence of convectional air flow on the detection efficiency for thoron as well as radon, the half-cutted hemispherical windbreak shown in Fig. 2 should be attached to cover the air inlets of the dosimeter. Figure 4 shows the relationship between air exchange rate of the detector housing of prototype R-T dosimeter and the height of half-cutted hemispherical windbreak which varied from 33 to $42 \mathrm{~mm}$. In all cases, forced wind was generated at the velocity of $6.0 \pm 1.0 \mathrm{~ms}^{-1}$. To minimize the influence of convectional air flow, the height of the windbreak was optimized to be $40 \mathrm{~mm}$ as shown in Fig. 4 .

On the other hand, it must be noticed that the half-cutted hemispherical windbreak may interrupt the entry of thoron gas into the dosimeter. In the steady state atmosphere, diffusion coefficient of thoron gas was evaluated to be $5.4 \times 10^{-4}\left(\mathrm{~m}^{2}\right.$ $\mathrm{s}^{-1}$ ) empirically. ${ }^{12}$ If the thoron gas was transported only by diffusion, thoron concentration should decrease in $17 \%$ during the time of flight from the edge of the windbreak of $40 \mathrm{~mm}$ height to the surface of the air inlet.

In thoron calibration exercise, thoron gas must be circulated and mixed by force to expose several dosimeters uniformly, since half-life of thoron is very short (56 s). Therefore, it could be regarded that the thoron concentration measured using the calibration factor for the practical R-T dosimeter corresponded to the concentration at the surface of the air inlet. This suggests the above decrease of thoron concentration may cause the underestimation of thoron.

However, it is difficult to assume the steady state condition in the actual environment, and in general, convectional air flow may cause an unstable detection efficiency of the dosimeter, and may also cause the irregular distribution of thoron concentration in the atmosphere. Therefore, from the practical point of view, an attachment of the windbreak to the R-T dosimeter could be justified as a countermeasure to the infiuence of the convectional air flow.

Figure 5 illustrates the schematic diagram of the updated practical R-T dosimeter. Main alterations are (a) diameters of the hemispheric chambers are optimized to be $110 \mathrm{~mm}$ and $70 \mathrm{~mm}$, (b) carbonated polycarbonate plastic is used as the housing material of the dosimeter, (c) the air inlet of the detector housing is covered with half-cutted hemispherical windbreak $(40 \mathrm{~mm}$ height), and (d) procedures in the assemblage of the dosimeter are simplified.

Radon or thoron entry rate, $R$ into $110 \mathrm{~mm} \phi$ and $70 \mathrm{~mm} \phi$ hemispheric chambers can be esti- 


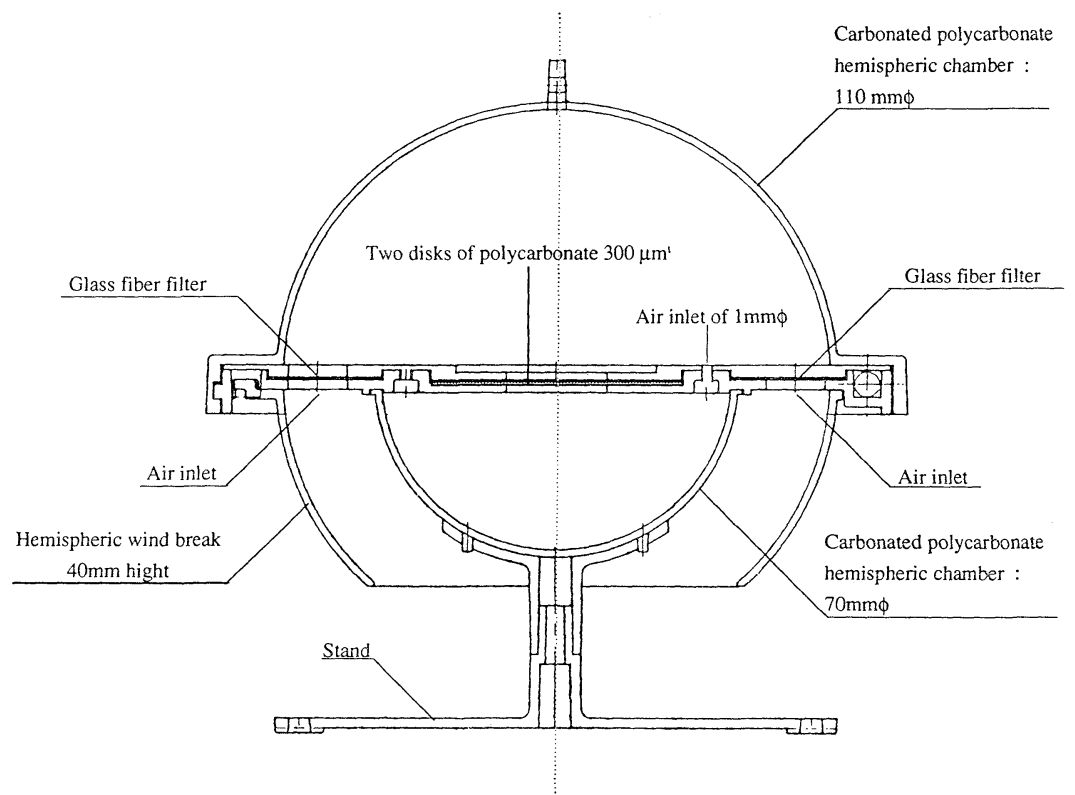

Fig. 5 A schematic diagram of the passive radon-thoron discriminative dosimeter for practical use (practical R-T dosimeter).

mated as follows:

$$
\begin{aligned}
& R_{110}=\frac{\eta_{110}}{\eta_{110}+\lambda} \\
& R_{70}=\frac{\eta_{70}}{\eta_{70}+\lambda} \times \frac{\eta_{110}}{\eta_{110}+\lambda}
\end{aligned}
$$

where $\lambda\left(\mathrm{h}^{-1}\right)$ is a decay constant of radon $(=$ 0.00756) or thoron $(=44.9), \eta_{110}\left(\mathrm{~h}^{-1}\right)$ is an air exchange rate between ambient air and $110 \mathrm{~mm} \phi$ hemispheric chamber through glass fiber filter set on the fan-shaped air inlet $\left(36.2 \mathrm{~cm}^{2}\right)$ as shown in Fig. 6, and $\eta_{70}\left(\mathrm{~h}^{-1}\right)$ is an air exchange rate between $110 \mathrm{~mm} \phi$ and $70 \mathrm{~mm} \phi$ hemispheric chambers through a pinhole air inlet $(1 \mathrm{~mm} \phi)$. Air exchange rates of the detector housing were estimated by gas chromatography (sample gas: $\mathrm{SF}_{6}$, carrier gas: $\mathrm{N}_{2}$ ), and it was shown that $\eta_{110}$ was $56.8 \pm 3.29\left(\mathrm{~h}^{-1}\right)$, and $\eta_{70}$ was $0.378 \pm 0.005$ $\left(\mathrm{h}^{-1}\right)$ respectively. Table 3 summarized the entry rates for radon and thoron gases in the $110 \mathrm{~mm} \phi$ and $70 \mathrm{~mm} \phi$ hemispheric chambers.

\section{Calibration factors for radon and thoron} concentrations

Calibration exercises of the practical R-T dosimeter were performed by using a radon chamber of Nagoya University and a radon-thoron mixed chamber of Waseda University in 1992. In the radon calibration exercise, 5 pieces of the practical R-T dosimeter were enclosed in the chamber of
Table 3 Entry rate of radon and thoron gases in

\begin{tabular}{|c|c|c|}
\hline \multirow{2}{*}{ Location } & \multicolumn{2}{|c|}{$\begin{array}{l}\text { Infiltration rate in the } \\
\text { hemispheric chamber }\end{array}$} \\
\hline & ${ }^{222} \mathrm{Rn}$ & $220 \mathrm{Rn}$ \\
\hline $110 \mathrm{~mm}$ hemisphere & $99.99 \%$ & $55.85 \%$ \\
\hline $70 \mathrm{~mm}$ hemisphere & $98.03 \%$ & $0.47 \%$ \\
\hline
\end{tabular}
the $110 \mathrm{~mm} \phi$ and $70 \mathrm{~mm} \phi$ hemispheric chambers.

$0.25 \mathrm{~m}^{3}$ which was connected to the radium source. Radon concentration during the exposure period was monitored continuously by a calibrated ionization chamber of Nagoya University, and radon exposure was estimated to be $3,145 \pm 157$ $\left(B q m^{-3} \mathrm{~d}\right)$. And the track densities of the polycarbonate films in $70 \mathrm{~mm} \phi$ and $110 \mathrm{~mm} \phi$ hemispheric diffusion chambers were found to be $127.5 \pm 10.3$ (tracks $\mathrm{cm}^{-2}$ ) and $91.5 \pm 11.2$ (tracks $\mathrm{cm}^{-2}$ ) respectively.

In the thoron calibration exercise, 5 pieces of the practical R-T dosimeter were enclosed in the chamber of $0.1 \mathrm{~m}^{3}$ which was connected to the radium and thorium sources. Both radon and thoron gases were sampled in several scintillation cells periodically. The activity concentration was measured continuously to estimate the disintegration curve by each scintillation cell, and 


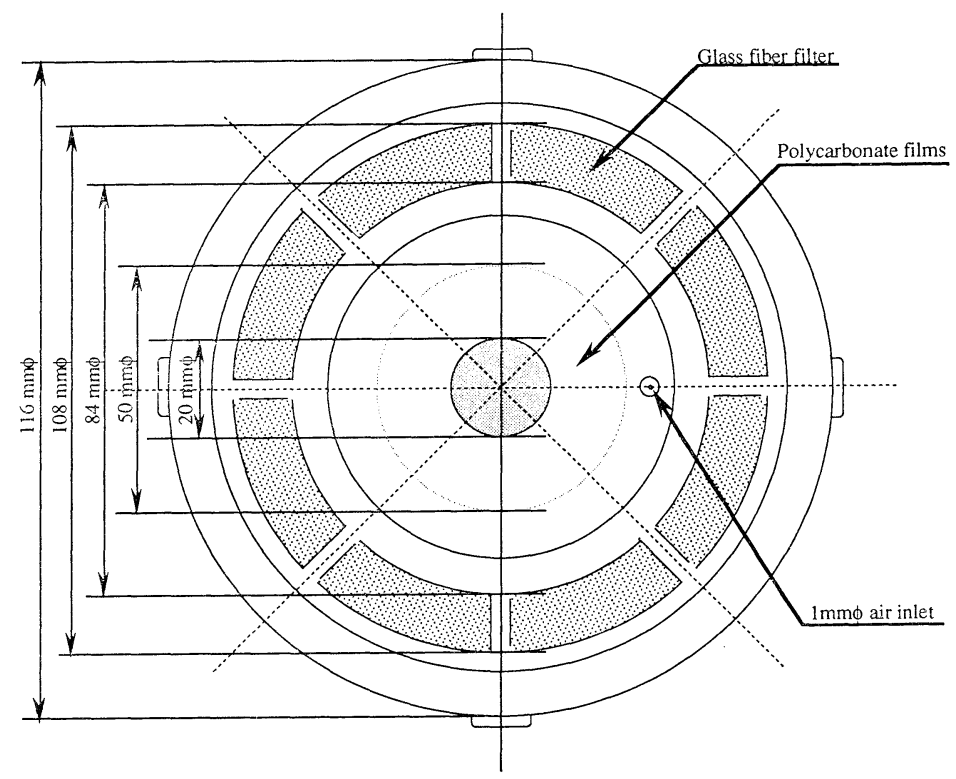

Fig. 6 A schematic diagram of the fan-shaped air inlet of the practical R-T dosimeter.

Table 4 The calibration factors of the practical R-T dosimeter for radon and thoron concentrations estimated by the calibration exercise using dosimetric standard radon and thoron chambers at Nagoya University and Waseda University in October, 1992. Values in the parentheses were estimated by Monte Carlo simulation and the air exchange rate estimated by the gas chromatography (sample gas: $\mathrm{SF}_{6}$, carrier gas: $\mathrm{N}_{2}$ ).

\begin{tabular}{|c|c|c|}
\hline \multirow{2}{*}{ Location } & \multicolumn{2}{|c|}{ Conversion factor (Tracks $\mathrm{cm}^{-2}$ per $\mathrm{Bq} \mathrm{m}^{-3} \mathrm{~d}$ ) } \\
\hline & ${ }^{222} \mathrm{Rn}$ (radon) & ${ }^{220} \mathrm{Rn}$ (thoron) \\
\hline \multirow[t]{2}{*}{$110 \mathrm{~mm}$ hemisphere } & $0.0291 \pm 0.0038$ & $0.0265 \pm 0.0065$ \\
\hline & $(0.0202)$ & $(0.0299)$ \\
\hline \multirow[t]{2}{*}{$70 \mathrm{~mm}$ hemisphere } & $0.0405 \pm 0.0038$ & $0.0000 \pm 0.0000$ \\
\hline & $(0.0375)$ & $(0.00012)$ \\
\hline
\end{tabular}

thoron concentration was evaluated by extrapolation of the curve. Radon and thoron exposures were estimated to be $460 \pm 16\left(\mathrm{~Bq} \mathrm{~m} \mathrm{~m}^{-3} \mathrm{~d}\right)$ and $1,214 \pm 83\left(\mathrm{~Bq} \mathrm{~m} \mathrm{~m}^{-3} \mathrm{~d}\right)$ respectively, and track densities of the polycarbonate films in $70 \mathrm{~mm} \phi$ and $110 \mathrm{~mm} \phi$ hemispheric diffusion chambers were found to be $18.5 \pm 2.2$ (tracks $\mathrm{cm}^{-2}$ ) and $45.6 \pm 6.9$ (tracks $\mathrm{cm}^{-2}$ ) respectively. Details of the thoron calibration exercise were shown by Kurosawa et al. ${ }^{20)}$

The calibration factors (tracks $\mathrm{cm}^{-2}$ per $\mathrm{Bq}$ $\mathrm{m}^{-3} \mathrm{~d}$ ) of the practical R-T dosimeter for radon and thoron concentrations were estimated as summarized in Table 4. Predicted calibration factors based on the Monte Carlo calculation were shown in the parentheses in Table 4, and were itemized into each nuclide as shown in Fig. 7.

The proper thing would be for predicted calibration factors to agree with the results of calibration exercises. However, as shown in Table 4, two kinds of calibration factors for thoron did not go together in the strictest sence. One of the reasons for the disagreement of these values should be the uncertainty in the estimation of effective vertical mean range of the $\alpha$-particle, $D f_{\mathrm{PD}}\left(E_{\mathrm{i}}\right)$ $(\mu \mathrm{m})^{10)}$ with high incident energy, which is left open as our future assignment.

These calibration factors must be regarded as interim ones which should be reexamined and 

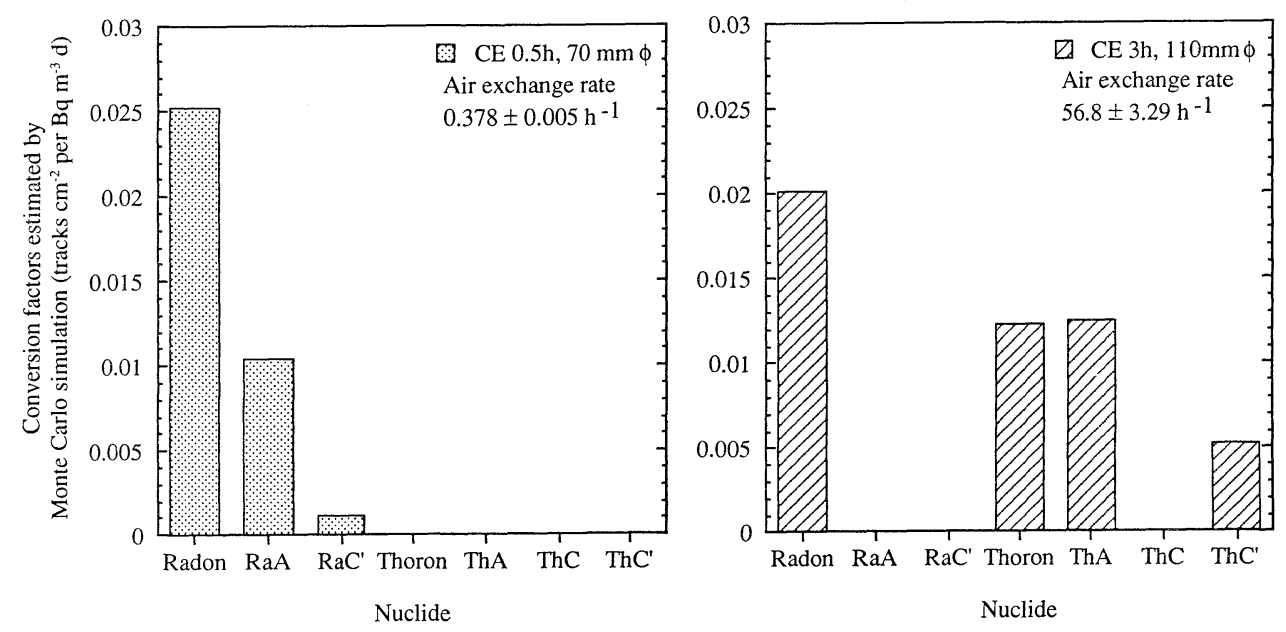

Fig. 7 Predicted calibration factors based on the Monte Carlo calculation itemized into each nuclide.

modified by periodical calibration exercises at above domestic standards for radon and thoron exposures. Especially, calibration exercise for thoron concentration is still developing to avoid the uneven distribution of thoron concentration in the chamber which caused the large variance of the calibration exercise. And to establish the international traceability, intercalibration exercises for radon and thoron exposures should be carried out at the Australian Radiation Laboratory, Australia, Environmental Measurement Laboratory and Environmental Protection Agency, USA, National Radiation Protection Board, UK, and other facilities.

4. Background track density and lower detection limit for radon and thoron concentrations

The background track density of the polycarbonate film (tracks $\mathrm{cm}^{-2}$ ) was estimated by applying the twenty dosimeters in the aged research air for 2 months as $V+(0.048 \pm 0.028) T$, where $V$ is background density of the virgin polycarbonate film (tracks $\mathrm{cm}^{-2}$ ) which is estimated as $4.4 \pm 2.1$, and $T(\mathrm{~d})$ is an exposure period.

In the case of 2 months exposure, background track density is estimated to be $7.3 \pm 2.7$ (tracks $\mathrm{cm}^{-2}$ ), and the lower detection limit for radon and thoron concentrations were estimated to be $5.1 \mathrm{~Bq} \mathrm{~m}^{-3}$ and $7.9 \mathrm{~Bq} \mathrm{~m} \mathrm{~m}^{-3}$ respectively which were based on the CURRIE's definition. ${ }^{19}$ )

5. Variances among twenty pieces of the practical R-T dosimeter

Figure 8 shows the variances of radon concentrations estimated by twenty pieces of the practical

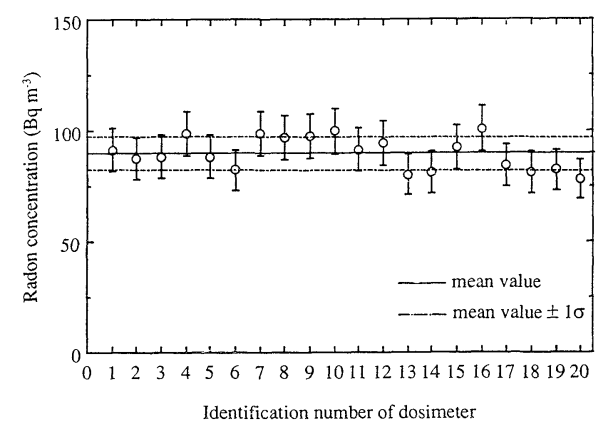

Fig. 8 The variances of radon concentrations estimated by twenty pieces of the practical R-T dosimeter which were placed in the concrete cellar for 2 months.

R-T dosimeter which were placed in the concrete cellar for 2 months. Vertical axis indicates the radon concentration in $\mathrm{Bq} \mathrm{m}^{-3}$ and horizontal axis indicates the identification number of each dosimeter. The distribution of the values was normal of which arithmetic mean was $89.8 \mathrm{~Bq}$ $\mathrm{m}^{-3}$ with a standard deviation of 7.4.

\section{Future subjects and activities}

In Japan, there are some findings which suggested that the enhanced concentration of thoron and thoron progeny tend to be found in the Japanese-style house whose interior wall is covered with fine soil as a surface coat ${ }^{3-5}$ ) and also showed that thoron and its progeny would contribute to the inhabitant a considerable effective dose. $^{6-8)}$ Therefore, nationwide survey of indoor thoron and radon concentrations should be planned and 
performed thoroughly together with an investigation on the construction style and materials. Interim survey using the prototype R-T dosimeter in 42 rooms of 21 houses in Hiroshima Prefecture suggested that some Japanese-style rooms with interior soil wall and tatami flooring tended to have enhanced concentrations of indoor thoron. ${ }^{13)}$ Large-scale national survey will indicate more detailed characteristics of the house with high risk of indoor thoron as well as radon. It also must be emphasized that thoron progeny concentrations in the breathing zone of the room contribute the effective dose to the inhabitants dominantly, which should be studied thoroughly.

According to the national statistics, ${ }^{14)}$ around $73 \%$ of all the Japanese houses are made of wood which has a potential risk of indoor thoron as well as radon. Since the radioactive half-life of thoron is very short (only $56 \mathrm{~s}$ ), reduction of thoron exhalation rate from the source materials into the indoor air should be studied to propose some remedial actions which are reasonably achievable taking economical and social factors into consideration.

\section{CONCLUSION}

A passive radon-thoron discriminative dosimeter for practical use has been developed. The body of the practical R-T dosimeter is made of two hemispheric diffusion chambers of carbonized plastic whose diameters are $110 \mathrm{~mm}$ and $70 \mathrm{~mm}$, respectively. These diameters are selected not only to improve the detection efficiency of both radon and thoron, but also to improve the discrimination ratio of radon to thoron. Inner surface of the detector housing is smooth and free from electrified charge to assure the uniform deposition of the radon and thoron progeny, because the detector housing is molded out of carbonized plastic as an anti-static countermeasure of which electric resistance is $2 \times 10^{3}$ to $5 \times 10^{3}$ $(\Omega \mathrm{cm})$. A structure of an air inlet has been improved to contact more tightly with a glass fiber filter and the air inlet is covered with a half-cutted hemispheric windbreak of $40 \mathrm{~mm}$ height to stabilize the influence of convectional air flow on the detection efficiency of both radon and thoron concentrations, and to protect the glass fiber filter from rain and dust. The results of calibration exercises and an interium measurement in the concrete cellar for two months proved that the practical R-T dosimeter has enough specifications to be used in the large-scale radon-thoron discriminative survey.

ACKNOWLEDGEMENTS: The authors would like to express their hearty appreciation for the cooperation and advice provided by many experts and organizations: first, Dr. M. URBAN and Dr. J. Schmitz of Karlsruhe Nuclear Research Center, Germany, who made available the use of their electrochemical etching device of their design together with many invaluable technical cooperation; second, Prof. Y. IKeBE and Dr. T. IIDA, Nagoya University, Japan and Prof. R. Kurosawa, Waseda University, Japan for their kind help in carrying out a series of radon and thoron calibration exercises and technical advice. And the authors wish to express their hearty appreciation to Mr. S. MasuYama, Japan Technical Research, Co. Ltd. for his technical cooperation and assistance in the manufacturing of the practical R-T dosimeter.

\section{REFERENCES}

1) UNSCEAR; Sources, effects and risks of ionizing radiation, pp. 24-25, New York, United Nations (1988).

2) UNSCEAR; Sources and effects of ionizing radiation, pp. 17-18, New York, United Nations (1993).

3) M. Doi, K. Fujimoto and S. Kobayashi; Separation of $\mathrm{Rn}$ and $\mathrm{Tn}$ concentrations with passive detectors, Proceedings of the 25th annual meeting of the Japan Health Physics Society (in Japanese), Tsukuba, Japan, May 24-25, p. 60 (1990).

4) T. Iida, K. Sone and Y. IKebe; Some problems on the measurement of radon concentrations by cup method, Proceedings of the 25th annual meeting of Japan Health Physics Society (in Japanese), Tsukuba, Japan, May 24-25, p. 63 (1990).

5) H. Yonehara and T. Aoyama; Concentration and distribution of ${ }^{220} \mathrm{Rn}$ and its progeny in a house, Proceedings of the 26th annual meeting of Japan Health Physics Society (in Japanese), Osaka, Japan, May 16-17, p. 16 (1991).

6) Q. Guo, M. Shimo, Y. Ikebe and S. Minato; The study on thoron progeny and radon progeny concentrations in different kinds of dwellings in Japan, Radiat. Prot. Dosim., 45, 357-359 (1992).

7) M. Shimo, K. Seki, Y. Jin, T. Iida, H. YamaNISHI and Y. IKEBE; Tn daughters concentration in several indoor and outdoor airs and lung dose due to $\mathrm{Rn}$ and Tn daughters-(1), Proceedings of the 24th annual meeting of the Japan Health 
Physics Society (in Japanese), Nagoya, Japan, May 30-31, p. 25 (1989).

8) M. Shimo, Q. Guo, Y. Ikebe and S. Minato; Tn daughters concentration in several indoor and outdoor airs and lung dose due to $\mathrm{Rn}$ and $\mathrm{Tn}$ daughters-(2), Proceedings of the 25th annual meeting of the Japan Health Physics Society (in Japanese), Tsukuba, Japan, May 24-25, p. 54 (1990).

9) K. Asano and N. Ito; Contents of radioactivity in the several building materials in Japan, Inside document of the Building Research Institute (in Japanese) (1989).

10) M. Doi, K. Fujimoto and S. Kobayashi; Etch pit formation model during chemical and electrochemical etching in polycarbonate foil, Radiat. Prot. Dosim., 37, 5-12 (1991).

11) M. Doi, S. Kobayashi and K. Fujimoto; A passive measurement technique for characterization of high-risk houses in Japan due to enhanced levels of indoor and thoron concentrations, Radiat. Prot. Dosim., 45, 425-430 (1992).

12) M. Doi, S. Kobayashi, K. Fujimoto and H. YoneHARA; Spatial distribution of thoron and radon concentrations in the ambient air of a traditional Japanese wooden house, Health Physics, 66, 43-49 (1994).

13) M. Dor and S. KobAYASHi; Characterization of
Japanese wooden houses with enhanced radon and thoron concentrations, Health Physics, 66, 274282 (1994).

14) Statistical Bureau; Management and Coordination Agency, Japan. Housing of Japan-summary of the results of 1988 housing survey of Japan, Japan Statistic Association, pp. 14-20 (1991).

15) H.J. Mason; Dielectric breakdown in solid insulation, In "Progress in Dielectrics," pp. 7-58, London, Heywood (1959).

16) A.S. Durrani and S.A.R. Al-NaJjar; The relationship between the pre-etched track length and the ECE track spot size, Nuclear Tracks, 12, 211214 (1986).

17) K. Fujimoto, M. Doi and S. KobaYASHI; Bulk etching rate of polycarbonate, Hoken Butsuri, 25, 221-226 (1990).

18) T. IIDA; Private communication (1990).

19) L.A. CurrIE; Limits for qualitative detection and quantitative determination, Anal. Chem., 40, 586593 (1968).

20) R. Kurosawa, S. Tokonami and F. Kamota; On the convenient test chamber for calibration of passive integrating radon-thoron monitor, environmental radon-Proceedings of the '91 radon symposium held at Kumatori, August 8-10, pp. 464-475 (1992). 